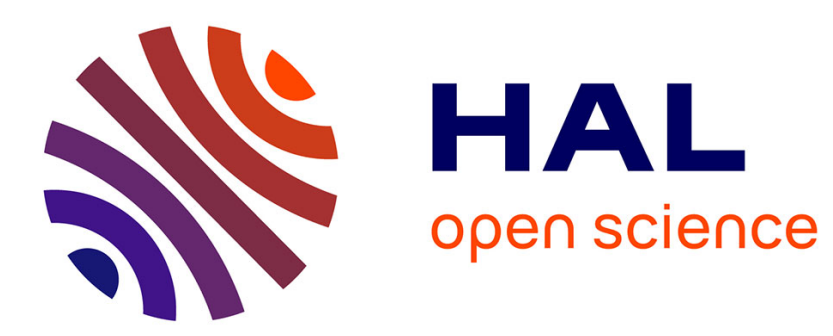

\title{
The impact of hurricane strikes on local cropland productivity: Evidence from the Carribean
}

\author{
Eric Strobl
}

\section{To cite this version:}

Eric Strobl. The impact of hurricane strikes on local cropland productivity: Evidence from the Carribean. 2009. hal-00393883

\section{HAL Id: hal-00393883 \\ https://hal.science/hal-00393883}

Preprint submitted on 10 Jun 2009

HAL is a multi-disciplinary open access archive for the deposit and dissemination of scientific research documents, whether they are published or not. The documents may come from teaching and research institutions in France or abroad, or from public or private research centers.
L'archive ouverte pluridisciplinaire HAL, est destinée au dépôt et à la diffusion de documents scientifiques de niveau recherche, publiés ou non, émanant des établissements d'enseignement et de recherche français ou étrangers, des laboratoires publics ou privés. 


\section{ECOLE POLYTECHNIQUE}

CENTRE NATIONAL DE LA RECHERCHE SCIENTIFIQUE

THE IMPACT OF HURRICANE STRIKES ON LOCAL CROPLAND PRODUCTIVITY:

EVIDENCE FROM THE CARIBBEAN

Eric STROBL

February 2009

Cahier $n^{\circ} \quad 2009-14$

DEPARTEMENT D'ECONOMIE

Route de Saclay

91128 PALAISEAU CEDEX

(33) 169333033

http://www.enseignement.polytechnique.fr/economie/

mailto:chantal.poujouly@polytechnique.edu 


\title{
THE IMPACT OF HURRICANE STRIKES ON LOCAL CROPLAND PRODUCTIVITY ${ }^{1}$ :
}

\author{
EVIDENCE FROM THE CARIBBEAN
}

Eric STROBL ${ }^{2}$

February 2009

Cahier $^{\circ} \quad$ 2009-14

\begin{abstract}
We empirically estimate the impact of hurricane strikes on local crop productivity in the Caribbean region. To this end we first identify local cropland at $1 \mathrm{~km} 2$ geographical units via Global Land Cover data. We then employ a windfield model combined with a power dissipation equation on hurricane track data to arrive at a scientifically based index of potential local destruction along these $1 \mathrm{~km} 2$ cropland grid cells for landfalling and passing hurricanes. Cropland productivity at the local level is approximated by annual net primary production values derived from satellite spectral reflectance data. This provides us with a panel of over 150,000 potentially affected cropland areas in the Caribbean over the period 2000-20006. Our econometric results indicate that cropland productivity is substantially reduced after a hurricane strike.
\end{abstract}

\footnotetext{
${ }^{1}$ I am grateful for financing from the Chaire Développement Durable of the Ecole Polytechnique.

${ }^{2}$ Dept. of Economics, Ecole Polytechnique, 91128 Palaiseau, France; email: eric.strobl@polytechnique.edu
} 


\section{Section I: Introduction}

Natural disasters are generally associated with considerable economic losses. Particularly alarming in this regard is not only the fact that the last three and a half decades have witnessed an increase in the number of such occurrences, but also that developing countries seem to be those bearing the brunt of these events and ultimately the economic consequences, thus possibly further adding to the perceived gap between the 'rich' and the 'poor'. For example, between 1970 and 2002 out of a total number of 6436 natural disasters, 77 per cent have taken place in the developing world. Moreover, the reoccurrence of such extreme events often tends to be concentrated in particular geographic areas, striking certain countries again and again, often with great severity. For instance, since 1984 Dominica has been struck by 9 different hurricanes, while Hurricane Georges caused losses of around 400 million US\$, constituting over 140 per cent of GDP, in the Caribbean islands of St. Kitts and Nevis in 1998.1

Importantly, natural disasters such as hurricanes can be particular damaging to agriculture. Since many developing countries tend to be relatively specialized in production, with particular emphasis on agricultural activities, understanding how such events affect the agricultural sector is arguably of upmost importance and of policy

\footnotetext{
I See Rasmussen (2004).
} 
relevance. ${ }^{2}$ Surprisingly, however, there is to the best of our knowledge specifically trying to quantify the effect of natural disasters on the agricultural sector in developing countries.

In this paper we just specifically set out to rectify this paucity by investigating the effect of hurricane strikes on cropland productivity in the Caribbean. In this regard, arguably focusing on hurricanes' impact on the Caribbean agricultural sector serves as an insightful case study. For one, over the last 50 years over 80 hurricanes made landfall in the region. Moreover, many of the small Caribbean islands and countries rely heavily on the agricultural sector to generate earnings.

Our approach relies heavily on non-economic data sources that we translate into economic measures in order to achieve the paper's goal. Firstly, we identify cropland within the Caribbean at a spatially extremely disaggregated level ( $1 \mathrm{~km}^{2}$ cells) via satellite derived spatial land cover data. Secondly, we resort to actual historical data tracking the movement of tropical storms across the affected region and employ a wind field model on the hurricane 'tracks' that allows us to calculate an approximation of the severity of winds experienced at this detailed geographical level. These local wind estimates are then used in conjunction with a power dissipation index to proxy local potential destructiveness of hurricanes. Finally, we construct measures of cropland

2 See Albala-Bertrand, J.M. (1993). 
productivity at the local level is by using annual net primary production values derived from satellite spectral reflectance data.

All our data sources combined allow us to construct a panel of over 150,000 cropland areas for which we can calculate the annual impact on cropland productivity of hurricane strikes over the 2000-2006 period. Our results show that the effect is rather short-lived, lasting about a year. Quantitatively, the effects on overall cropland productivity tend to be moderate, although over our sample period the impact was on occasion as large as a 8 per cent reduction in cropland productivity.

The remainder of the paper is as follows. In the next section we briefly describe the basic nature of hurricanes and their potential destructiveness. In Section III we outline the wind field model and power dissipation equation used to derive a local index of local destructiveness. Section IV describes our data sources. Some destruction estimates using our proxy are given in Section $\vee$. We econometrically investigate the impact of hurricanes on cropland productivity in the region in Section VI. Finally, concluding remarks are provided in the last section.

\section{Section II: Some Basic Facts about Hurricanes and their Destructive Power}

A tropical cyclone is a meteorological term for a storm system, characterized by a low pressure system center and thunderstorms that produces strong wind and flooding rain, which forms almost exclusively, 
and hence its name, in tropical regions of the globe. ${ }^{3}$ Depending on their location and strength, tropical cyclones are referred to by various other names, such as hurricane, typhoon, tropical storm, cyclonic storm, and tropical depression. Tropical storms in the North Atlantic and the North East Pacific region, as we study here, are generally termed hurricanes if they are of sufficient strength. ${ }^{4}$ In terms of its structure, a hurricane will typically harbor an area of sinking air at the center of circulation, known as the 'eye, where weather in the eye is normally calm and free of clouds, though the sea may be extremely violent. ${ }^{5}$ Outside of the eye curved bands of clouds and thunderstorms move away from the eye wall in a spiral fashion, where these bands are capable of producing heavy bursts of rain, wind, and tornadoes. The typical structure of a hurricane is depicted in Figure 1. Hurricane strength tropical cyclones are typically about $483 \mathrm{~km}$ wide, although they can vary considerably. The season for hurricanes in the two regions can start as early as the end of May and last until the end of November.

Hurricane damages in terms of agriculture typically take a number of forms. Firstly, the strong winds associated with hurricanes may cause considerable structural damage to crops. Secondly, strong rainfall can result in extensive flooding and, in sloped areas, landslides. Finally, the

\footnotetext{
3 The term "cyclone" derives from cyclonic nature of such storms, with counterclockwise rotation in the Northern Hemisphere and clockwise rotation in the Southern Hemisphere.

${ }^{4}$ Generally at least $119 \mathrm{~km} / \mathrm{hr}$.

5 National Weather Service (October 19, 2005). Tropical Cyclone Structure. JetStream An Online School for Weather. National Oceanic \& Atmospheric Administration.
} 
high winds pushing on the ocean's surface cause the water near the coast to pile up higher than the ordinary sea level combined with the low pressure at the center of the weather system and the bathymetry of the body of water results in storm surges. Storm surges can cause severe salt contamination of agricultural areas, where flooding on the coast may occur 3-5 hours before the arrival of the center of the hurricane. ${ }^{6}$

\section{Section III: Hurricane Wind Damage Index}

While the extent of potential damages caused by hurricanes may depend on many factors, such as slope of the continental shelf and the shape of the coastline in the landfall region in the case of storm surges, it is typically measured in terms of wind speed, and we similarly follow this approach. More specifically, our hurricane wind damage index is based on being able to estimate local wind speeds at any particular locality where a hurricane strength tropical storm passes over or nearby. To do so we rely on the meteorological wind field model developed by Boose et al (2004). ${ }^{7}$, which provides estimates of wind field velocity of any point relative to the 'eye' of the hurricane. This model is based on Holland's well known equation for cyclostrophic wind ${ }^{8}$ and sustained wind velocity at any point $P$ is estimated as:

\footnotetext{
6 Yang (2007).

7 This wind field model was, for instance, verified by the authors on data for Puerto Rico.

8 See Holland (1980). One may want to note that Holland's model is an axisymmetric model in that the true asymmetric nature of a hurricane cannot be represented. There is,
} 
$V_{s}=F\left[V_{m}-S(1-\sin (T)) \frac{V_{h}}{2}\right]\left[\left(\frac{R_{m}}{R}\right)^{B} \exp \left(1-\left[\frac{R_{m}}{F}\right]^{B}\right)\right]^{\frac{1}{2}}$

where $V_{m}$ is the maximum sustained wind velocity anywhere in the hurricane, $T$ is the clockwise angle between the forward path of the hurricane and a radial line from the hurricane center to the point of interest, $\mathrm{P}, \mathrm{V}_{\mathrm{h}}$ is the forward velocity of the hurricane, $\mathrm{R}_{\mathrm{m}}$ is the radius of maximum winds, and $\mathrm{R}$ is the radial distance from the center of the hurricane to point $\mathrm{P}$. The relationship between these parameters and $\mathrm{P}$ are depicted in Figure 2. Of the remaining ingredients $F$ is the scaling parameter for effects of surface friction, $\mathrm{S}$ the scaling parameter for asymmetry due to the forward motion of the storm, and B the scaling parameter controlling the shape of the wind profile curve. The peak wind gust velocity at point $\mathrm{P}$ can then be estimated via:

$V_{g}=G V_{S}$

where $\mathrm{G}$ is the gust wind factor.

The next step entails translating these wind field calculations into potential damage estimates. As noted by Emanuel (2005), both the monetary losses in hurricanes as well as the power dissipation of these storms tend to rise roughly as the cube of the maximum observed wind speed rises. Consequently, he proposes a simplified power dissipation

however, no consensus on how such asymmetry should be modeled; see Bao et al (2005). 
index that can serve to measure the potential destructiveness of hurricanes as9:

$\mathrm{PDI}=\int_{0}^{\tau} V^{3} d t$

where $\mathrm{V}$ is the maximum sustained wind speed, and $\tau$ is the lifetime of the storm as accumulated over time intervals t. Here we modify this index to obtain an index of potential damage of a hurricane at a particular spatial locality. More precisely, the total destruction due to a storm rin country $i$ at locality $\mathrm{j}$ in year $\mathrm{t}$ is:

$\mathrm{HD}_{\mathrm{i}, \mathrm{j}, \mathrm{r}, \mathrm{t}}=\sum_{0}^{\tau} V_{i, j, r, \mathrm{~s}}^{3} \quad$ if $\mathrm{V} \geq 119 \mathrm{~km} / \mathrm{jr}$

(4)

The index in (4) can then be used to calculate annual total destruction in local $\mathrm{j}$ by aggregating all its values over a year $\mathrm{t}$.

\section{Section III: Data Sources}

Our geographical region of focus are the 25 countries/territories of the Caribbean, where we depict these in Figure 3. To construct our panel of localities we rely on a number of data sources, as described below.

9 This index is a simplified version of the power dissipation equation $P D=2 \pi \int_{0}^{t} \int_{0}^{r_{0}} C_{D \rho}|V|^{3} r d d t$ where the surface drag $\left(C_{D}\right)$, surface air density $(\rho)$, and the radius of the storm ( $\left.r_{0}\right)$ are taken as given since these are generally not provided in historical track data. Emanuel (2005) notes that assuming a fixed radius of a storm is likely to introduce only random errors in the estimation. He similarly argues that surface air density varies over roughly 15\%, while the surface drag coefficient levels off at wind speeds in excess of $30 \mathrm{~m} / \mathrm{s}$, so that assuming that their values are fixed is not unreasonable. 


\section{A. Humicane Data}

For data on hurricanes in the Central American and Caribbean region we rely on the North Atlantic Hurricane database (HURDAT), maintained by the National Hurricane Center (NHC). The HURDAT database consists of six-hourly positions and corresponding intensity estimates in terms of maximum wind speed of tropical cyclones in the North Atlantic Basin since 1851 and is the most complete and reliable source of North Atlantic hurricanes. ${ }^{10}$ We depict all tropical storm tracks in the region since 1997 in Figure 4, where the segments in red signify the part of tropical storms that reached at least hurricane level of strength. As can be seen, throughout the region there has been considerable tropical storm activity with ??? tropical storms having navigated the region. However, one may want to note that a large part of this activity has been at a level deemed not (relatively) important in terms of potential damages caused as suggested by speeds of at least hurricane strength.

\section{B. Cropland Productivity}

Unsurprisingly, agricultural measures of cropland productivity, such as crop yields, at a fine spatial data over any meaningfully large space and time are essentially non-existent, particularly for developing countries. In order to obtain a proxy of cropland productivity we instead resort to the concept of 'net primary production' (NPP). 'Production' in this regard

\footnotetext{
10 Elsner and Jagger (2004).
} 
refers to the creation of new organic matter. For example, when a crop of wheat grows, new organic matter is created by the process of photosynthesis, where light energy is converted to energy stored in plants, in turn spurning plant growth. 'Gross primary production' (GPP) thus refers to the rate at which an ecosystem's producers convert solar energy into chemical energy as biomass. Since plants use some of their energy for respiration, the amount of energy available for energy consumption by consumers is just gross primary production minus respirations costs, i.e., NPP, usually measured in terms of $\mathrm{kcal} / \mathrm{m}^{2} /$ year. In essence NPP quantifies the conversion of atmospheric $\mathrm{CO}^{2}$ into plant biomass. As noted by Hicke et al. (2004), NPP can change in response to shifts in different crops, changes in crop management practices (ex: fertilization, irrigation, pest management etc.), and climate (ex: precipitation, temperature, solar radiation). One may also want to note that one of the advantages for using NPP to proxy cropland productivity over large areas and over time is that it, unlike economic data, provides a common metric among different crop types, thereby facilitating comparisons and aggregation over all crop types. As a matter of fact, there numerous studies have used yield data to derive NPP estimates in order to assess cropland productivity across areas; see, for instance, Monfreda et al (2008) and Veron (2002) to name a few. 
The most natural starting point to try and estimate NPP for a particular spatial location would theoretically of course seem to be through actual ground level measurement. However, even part from questions of cost and organizational feasibility, using ground data to measure local NPP is exceedingly difficult over large geographical areas because of the spatial variability of environmental conditions and the limitations in direct measurement techniques; see Goetz and Prince (1999). An attractive alternative in this regard is to instead use NPP measurements derived from satellite data on spectral reflectance. More precisely, in contrast to NPP measures based on interpolations from widely separated ground point observations, remotely sensed data are spatially contiguous and relatively frequent (generally daily). The physical basis for the observed correlation between spectral reflectance and NPP is the existence of a relationship between spectral reflectance and the absorption of solar radiation by vegetation canopies, and in turn the link between the amount of absorbed photosynthetically active radiation and its utilization for NPP. ${ }^{11}$ To then actually deriving NPP from APAR one needs an estimate of the production efficiency, $\varepsilon$. $\varepsilon$ can, however, potentially vary widely across different plant types and biomes for two reasons since respiration costs appear to increase with plant size and suboptimal climatic conditions can also attribute to its variability. The main

\footnotetext{
11 This relationship was first noted by Monteith (1972).
} 
challenge to then actually deriving quantitative measures of NPP from satellite reflectance data is estimating this $\varepsilon .{ }^{12}$

In this paper we use the MOD17A2 NPP measures derived from images on spectral reflectances of terrestrial vegetation using the Moderate Resolution Imaging Spectroradiometer (MODIS) on the NASA Earth Observing System (ES) Terra satellite. More precisely, the Earth Observing System Data Information System (EOSDIS) computes calibrated and atmospherically corrected reflectances from each spectral channel of the MODIS sensor for each cloud free pixel. Daily GPP computation at the local level then rests additionally on the biome type, which is recomputed annually, the fraction of photosynthetically absorbed radiation, which can change weekly, and the daily surface climate conditions, which change diurnally. GPP and NPP and are then calculated using these input variables and the complex ecosystem model BIOME-BGC. Global data at the $1 \mathrm{~km}$ spatial level is calculated for GPP daily and summed every 8 days, while NPP measures are provided at an annuals basis at the end of the year since plants grow during different parts of the year.

While NPP estimates in the MOD17A2 data set are provided for all land areas, we are for the purposes of the current paper only interested in

12 It is of course of interest to know how well satellite derived measures of NPP are able to approximate their from ground data computed alternatives. In this regard, Lobell et al. (2002), for instance, have shown that there is good agreement between yield and satellite derived estimates of NPP for the US. 
those pertaining to cropland areas. To identify these we resort to the 2000 Global Land Cover (GLC 2000) data set. The GLC 2000 data classifies land across the globe into 22 distinct land cover categories based on 14 months (1 Nov. 1999 - 31 Dec. 200) of daily 1-km resolution satellite data acquired over the whole globe by the VEGETATION instrument on-board the SPOT 4 satellite and delivered as multi-channel daily mosaics ("S1" format). We first overlaid the data into the grid format of the MOD17A2 via krigging. We then used the land cover categories (i) cropland (upland cropland or inundated/flooded crops), (ii) mosaic of cropland / shrub or herbaceous cover, and (iii) mosaic of cropland / tree cover / other natural vegetation to identify those $1 \mathrm{~km}$ cells that are used for cropland. We provide a graphical depiction of these croplands in Figure 5.

One may want to note that our identification of cropland will necessarily suffer from two weaknesses. Firstly, we cannot take account of any changes in land cover over our sample period since the data is time invariant. Secondly, our identification crucially depends on the accuracy of the classification system of the GLC 2000. In this regard, one would suspect that small scale farming may not be captured in our analysis.

\section{Other Data}

As noted above, one of the factors that can affect NPP is the local climate, such as rainfall and temperature, that a region is exposed to. To 
control for such factors we climatic data from the Willmott, Matsuura and Collaborators' Global Climate database at the University of Delaware. More specifically, this provides monthly time series over the 1900-2006 period on precipitation and temperature at 0.5 times 0.5 degree cells of the global land area. Since the grid classification is more aggregate than our $1 \mathrm{~km}^{2}$ schemata used for our measures cropland productivity we interpolate values via distance weighting to arrive at measures at a similar spatial aggregation as our NPP data.

Overall the collection of our data sources above results in annual values of hurricane destruction, cropland productivity, and climatic variables for 157,116 local cropland regions at a $1 \mathrm{~km}^{2}$ size over the 2000 2006 period. Summary statistics of these are provided in Table 1.

\section{Section IV: Hurricane Destruction Estimates}

To calculate local and aggregate wind speed damage estimates due to hurricanes, we first need to estimate local wind speeds experienced by relevant localities. One should note that of all the parameters necessary to estimate (1) and (2) some are given by the hurricane best track data, while for others values need to be assumed as in Boose et al (2004). In particular, the raw hurricane data set provides values for maximum sustained wind velocity, $V_{m}$, at particular locations at particular time intervals and from these one can then estimate $V_{h}$, the 
forward velocity, and, relative to the point of interest $\mathrm{P}$, the clockwise angle between the forward path of the hurricane $T$, and, $R$, the radial line from the hurricane center.

The scaling parameters, F, S, B, and G in (1) and (2) control for surface friction, forward motion of the hurricane, the shape of the hurricane, and the gust factor, respectively. Here we use the figures as suggested by Boone et al (2005). In particular, $\mathrm{F}$ is assumed to take on values of 1.0 and 0.8 for points on water and land respectively, while G uses respective values of 1.2 and 1.5 for these surface types. S and B are assumed to be 1.0 and 1.3, respectively. Finally, one should note that while the radius of maximum winds, $R_{m}$, i.e., the distance between the center of the cyclone and its band of strongest winds, is considered to be an important parameter in tropical cyclone forecasting, historical hurricane best track data generally do not provide estimates of this parameter. ${ }^{13}$ We thus assume this to take on the value of $50(\mathrm{~km})$, which corresponds to its average value found for hurricanes with central pressures falling between 909 and 993 hPa. ${ }^{14}$

With these parameter inputs in hand the wind field model in (1)-(2) enables us to estimate the wind intensity experienced by any location relative to the position and maximum wind speed of a hurricane (as given

13 This parameter is traditionally measured by reconnaissance aircraft in the Atlantic basin, so that there is no information in this regard for older hurricanes.

14 See Hsu and Yana (1998). This roughly corresponds to the central pressures of tropical storms of hurricane strength, where central pressure is inversely related to strength. 
by the best track data). However, one may want to note that while the raw cyclone data provides six hourly positions of tropical cyclones, these storms may travel considerable distance within six hours. Thus in order to ensure that we do not neglect areas that may be affected but do not fall within any significant distance (in the sense of experiencing severe winds) in our six hour windows, we linearly interpolated the positions $\mathrm{P}$ and wind speeds between the six hourly data to obtain three hourly track data. ${ }^{15}$ In choosing all possible positions for which to calculate wind speeds experienced, we compiled the location of the center of each grid cell used for the population data within our region of interest.

In terms of applying our wind field model to obtain local wind intensity estimates for the Caribbean region, we then followed each tropical cyclone over each point of the interpolated track and calculated the wind intensity relative to the center of each grid cells in the schemata provided by the population data as long as these fell within $500 \mathrm{~km}$ of the hurricane's location. ${ }^{16}$ This provided us with a complete set of estimates of wind fields experienced by all spatially relevant localities relative to each position of each tropical cyclone. We were then able to calculate local destruction according to our index of (4).

15 One should note that interpolating the track data to obtain more frequent observations of the tropical cyclone is standard in the literature; see, for instance, Jagger and Elsner (2006).

16 Hurricanes have been observed to reach up to a maximum of size of $1000 \mathrm{~km}$ in diameter. 
We first depict all hurricane tracks that according to our wind damage index were associated with at least some damage in one of the countries in the CAC region in Figure 6 , where the red portions of the tracks indicate when these reached hurricane strength. Accordingly, only ??? storms, i.e., ?? per cent of all tropical storms that occurred since 1999 in the North Atlantic and Eastern North Pacific, came within close enough distance and reached high enough strength to affect local areas of the countries in the Caribbean region according to our HD index.

As a demonstration of how our HD index translates into estimates of local destruction for individual hurricane occurrences we next calculated and plotted its value over all affected localities for Hurricanes David in Figure 7, where shading moving from yellow to red indicates the rising scale of damages (measured in terms of their contribution on a national scale because of the population weights). One may want to note that Hurricane Dennis was an early-forming major hurricane in the Caribbean and Gulf of Mexico during the very active 2005 Atlantic hurricane season. Dennis was the fourth named storm, second hurricane, and first major hurricane of the season. In July, the hurricane set several records for early season hurricane activity, becoming both the earliest formation of a fourth tropical cyclone and the strongest Atlantic hurricane ever to form before August. Dennis hit Cuba twice as a Category 4 hurricane on the Saffir-Simpson Hurricane Scale, and made landfall on the Florida 
Panhandle in the United States as a Category 3 storm less than a year after Hurricane Ivan did so. Dennis caused at least 89 deaths (42 direct) in the U.S. and Caribbean and caused approximately $\$ 2.23$ billion (2005 US dollars) in damages in the Caribbean, primarily on Cuba.

As can be seen from Figure 8, Hurricane Dennis only made landfall at hurricane strength in Cuba, causing damages throughout the island. Noteworthy in this regard is that the extent of damages differed widely, where being close to the actual traveled track does not necessarily mean large destruction in terms of national importance because of a non-even spread of population densities. ${ }^{17}$ One may also want to take note that while no other islands were directly struck in terms of landfall, Hurricane Dennis' winds were strong enough to affect Haiti, Jamaica and small parts of the Bahamas.

In Figure 9 we plot the average degree of destruction suffered by individual localities in the region over our sample period - where the scale increases as colors change from yellow to red. As can be seen, the potential damage to croplands even with countries is not evenly distributed. For instance, north eastern Cube suffered to a much greater extent than other parts of the countries.

Averaging the values calculated from the HD proxy over all hurricanes $r$ can also serve to compare the destructiveness of hurricanes

17 Most obviously, some areas, despite being very close to the actual track, were estimated to have zero damages because the local population was zero. 
relative to each other in terms of the damages done across economies. We show a ranking of these in terms of average destruction in Table 3. As can be seen, croplands in the Cayman Islands were potentially the most affected, followed by Jamaica, Anguilla, and the Virgin Islands. In contrast, over our sample period Costa Rica experienced no potential hurricane destruction to its croplands. Comparing the actual damage index figures across countries, one may want to note the large dispersion, with the top affected having values multiple times those at the lower half of the table.

\section{Section V: Econometric Analysis}

Our main econometric task is to investigate the macroeconomic impact of hurricane strikes in the Central American and Caribbean region using our index of destruction. To do so we take our panel of countries for which we also have macroeconomic data and specify a simple growth equation:

$\log (N P P)_{i, j, t}=\alpha+\beta_{1} R_{A I N} i_{i, j}+\beta_{2} T_{E M P} P_{i, j, t}+\beta_{3} H_{D_{i, j, t}}+\varepsilon_{i, t}$

where NPP is net primary production, RAIN precipitation, TEMP temperature, HD our index from (4) summed over a year, and $\varepsilon$ is an error term. One worry with estimating is that we do not control for the different types of crops and that some crops may be more affected by hurricane 
strikes than others. If the choice of crops depends at least to some extent on the probability that a hurricane strikes the area, then this could bias our estimate of the coefficient on HD. We assume here that this effect is time invariant and control for it by running a fixed effects estimator, which purges all time invariant unobservables from the equation. Another concern is that, particular due to our use of spatially very disaggregated data, that there may be spatial dependence across localities, causing spatial correlation among the error terms. To take account of this we employ the nonparametric covariance matrix estimator proposed by Driscoll and Kray (1998), which produces heteroskedasticity consistent standard errors that are robust to very general forms of spatial and temporal dependence.

Our results of estimating (4) are given in Table 3, where year specific time dummies are included but not reported. In the first column we only include our climatic variables. As can be seen, while rain has a positive impact on NPP, the is no such effect in terms of temperature. This may be because of the interpolation procedure underlying fitting the climatic data onto our $1 \mathrm{~km}^{2}$ grid cells. However, more likely this is in large part due to the fact that temperature tends, in contrast to rainfall, vary much less locally, and thus that any effect of temperature is captured by our time dummies. 
In the second column we include our HD index, which turns out to be negative but insignificant. In contrast, the t-1 lag of the index, as shown in the third column, is statistically significant. We suspect this to be due firstly because most hurricanes take place in the third and fourth quarter of any calendar year and hence their effect may only be picked up in the NPP measures of the following calendar year. Additionally, it could also be that calendar years and growing seasons of crops are unlikely to perfectly overlap.

As can be seen including further lags (up to t-3) produces no additional long term effect of a hurricane strike on cropland productivity. As a robustness check we re-ran (5) only including our significant variables, namely $\mathrm{HD}$ at $\mathrm{t}_{-}-1$ and RAIN at $t$, but the coefficient on HD remains significant and of similar size. One possibility may also be that RAIN is picking up some of the damage due to hurricanes since these tend to be heavily correlated with strong rainfall particularly in the outer wind bands of a hurricane. However, as shown in the last column, excluding RAIN changes little in terms of the coefficient on HD.

We can also use our results to gain some insight into the economic significance of hurricane strikes on cropland productivity. More specifically, our estimated coefficient on the HD at $t-1$ suggests that the average hurricane reduces cropland productivity by about 0.7 
percentage points. In contrast, the largest annual exposure could reduce productivity of croplands up to 6.1 percentage points.

\section{Section VI: Concluding Remarks}

In this paper we investigated the impact of hurricane strikes on local cropland productivity in the Caribbean region using non-economic data and methods to construct economic measures. Our results show that the impact has been unevenly distributed across the regions, with countries/territories like Cayman Islands and Jamaica having been potentially most affected over our sample period (2000-2006). Our econometric analysis demonstrates that hurricane strikes have indeed had a statistically significant impact on cropland productivity. More specifically, our estimates suggest that the average hurricane reduces cropland productivity by about 0.7 percentage points, but that local cropland may experience a loss of up to over 6 percentage points. 


\section{REFERENCES}

Anbarci, N., Escaleras, M., and Register, C. (2005). "Earthquake Fatalities: The Interaction of Nature and Political Economy", Joumal of Public Ec onomics, 89, pp. 1907-1933.

Arellano, M. and Bond, S. (1991). "Some Test of Specification for Panel Data: Monte Carlo Evidence and an Application to Employment Equations", Review of Economic Studies, 58, pp. 277-297.

Bao, S., Xie, L., and Pietrafesa, L. (2005). "An Asymmetric Hurricane Wind Model for Storm Surge and Wave Forecasting", paper presented at the 27th Conference on Hurricanes and Tropical Meteorology.

Bluedorn, J.C. (2005). "Hurricanes: Intertemporal Trade and Capital Shocks", Nuffield College Economics Paper 2005-W22.

Boose, E., Serrano, M. and Foster, D. (2004). "Landscape and Regional Impacts of Hurricanes in Puerto Rico", Ecological Monograph, 74, pp. 335352.

Bruno, G. (2005). "Approximating the bias of the LSDV estimator for dynamic unbalanced panel data models", Economics Letters, 87, pp. 361-366.

Dilley, M., Chen, R., Deichmann, U., Lerner-Lam, A., Arnold, M., Agwe, J., Buys, P., Kjekstad, O., Bradfield, L., and Yetman, G. (2005). "Natural Disaster Hotspots: A Global Risk Analysis", Disa ster Risk Ma na gement Series, 5, Hazard Management Unit, World Bank.

Elsner, J. (2003). "Tracking Hurricanes", Bulletin of the American Meteorologic al Soc iety, 84, pp. 353-356.

Emanuel, K. (2005). "Increasing Destructiveness of Tropical Cyclones over the past 30 Years", Nature, $4^{\text {th }}$ August 2005, pp. 686-688.

Hallegate, S., Hourcade, J., and Dumas, P. (2007). "Why Economics Dynamics Matter in Assessing Climate Change Damages: Illustration on Extreme Events", Ecological Economics, 62, pp. 330-340.

Holland, G. (1980). "An Analytic Model of the Wind and Pressure Profiles in Hurricanes", Monthly Weather Review, 106, pp. 1212-1218. 
Horwich, G. (2000). "Economic Lessons of the Kobe Earthquake", Economic Development and Cultural Change, 48, pp. 521-542.

Hsu, S. and Yana, Z. (1998). "A Note on the Radius of Maximum Wind for Hurricanes", J oumal of Coastal Research, 14, 667-668.

International Monetary Fund (2001). Republic of Armenia-Interim Poverty Reduction Strategy Paper.

Available at: http://www.imf.org/external/NP/prsp/2001/arm/01/

Jagger, T., and Elsner, J. (2004). "A Hierarchial Baysian Approach to Seasonal Hurricane Modeling", J oumal of Climate, 17, pp. 2813-2827.

Jagger, T., and Elsner, J. (2006). "Climatology Models for Extreme Hurricane Winds near the United States", J oumal of Climate, 19, pp. 32203236.

Judson, R. and Owen, A. (1996). "Estimating Dynamic Panel Models: A Practical Guide for Macroeconomists", Finance and Ec onomic s Disc ussion Series, 1997-3. Washington: Federal Reserve Board.

Jarvinen, B., Neumann, C., and Davis, M. (1998). "A Tropical Cyclone Data Tape for the North Atlantic Basin, 1886-1983: Contents, Limitations and Uses", NOAA Technical Memorandum NWS NHC 22.

Kahn, M. (2005). "The Death Toll from Natural Disasters: The Role of Income, Geography, and Institutions", Review of Ec onomic s and Statistics, 87, pp. 271-284.

Kiviet, J. (1995). "On Bias, Inconsistency and Efficiency of Various Estimators in Dynamic Panel Data Models", Joumal of Ec onometrics, 68, pp. 53-78.

McGranahan, G., Balk, D., and Anderson, B. (2007). "The Rising Tide: Assessing the Risks of Climate Change and Human Settlements in Low Elevation Coastal Zones", Environment and Urba nization, 19, pp. 17-37.

Noy, I. and Aekkanush, N. (2007). "What do Exogenous Shocks Tell Us about Growth Theories", Department of Economics, University of Hawaii, Working Paper.

Noy, I. (2008). "The Macroeconomic Consequences of Natural Disasters", J oumal of Development Ec onomics, forthcoming. 
Pielke, R., Gratz, J., Landsea, C., Collings, D. (2008). "Normalized Hurricane Damages in the United States: 1900-2005", Natural Haza rds Review, 29, pp. 29-42.

Ramcharan, R. (2007). "Does the Exchange Rate Regime Matter for Real Shocks? Evidence from Windstorms and Earthquakes", Joumal of Intemational Ec onomics, 73, pp. 31-47.

Rappaport, J. and Sachs, J. (2003). "The United States as Coastal Nation", J oumal of Ec onomic Growth, Vol. 8. pp. 5-46.

Rasmussen, D. (2004). "Macroeconomic Implications of Natural Disasters in the Caribbean", IMF Working Paper, WP/04/224.

Toya, H. and Skidmore, M. (2007). "Economic Development and the Impacts of Natural Disasters", Ec onomic s Letters, 94, pp. 20-25.

Vickery, P., Skerlj, P., Lin, J., Twisdale, L., Young, M., and Lavelle, F. (2006). "HAZUS-MH Hurricane Model Methodology LL: Damage and Loss Estimation", Natural Haza rds Review, May 2006, pp. 94-103.

Woo, G. (1998). The Mathematics of Natural Disasters, Imperial College Press.

Yang, D. (2007). "Coping with Disaster: The Impact of Hurricanes on International Financial Flows, 1970-2002", Advances in Economic Analysis $\&$ Policy (B.E. Press), forthcoming. 
Table 2: Mean Hurricane Destruction experienced in Croplands by Country/Territory

\begin{tabular}{|l|c|}
\hline Country/Territory & Wind Destruction \\
\hline CAYMAN ISLANDS & 347.0138 \\
\hline JAMAICA & 213.4461 \\
\hline ANGUILLA & 178.8457 \\
\hline VIRGIN ISLANDS & 161.7454 \\
\hline SAINT KITTS AND NEVIS & 145.892 \\
\hline BELIZE & 119.5626 \\
\hline TURKS AND CAICOS ISLANDS & 108.6281 \\
\hline CUBA & 99.56162 \\
\hline ANTIGUA AND BARBUDA & 79.38261 \\
\hline ARUBA & 75.60234 \\
\hline BAHAMAS & 74.66311 \\
\hline MONTSERRAT & 69.56258 \\
\hline NETHERLANDS ANTILLES & 69.23227 \\
\hline PUERTO RICO & 66.95869 \\
\hline GUADELOUPE & 42.64012 \\
\hline DOMINICA & 20.62569 \\
\hline SAINT VINCENT AND THE GRENADINES & 19.85767 \\
\hline TRINIDAD AND TOBAGO & 19.23702 \\
\hline HAITI & 13.73098 \\
\hline DOMINICAN REPUBLIC & 11.39064 \\
\hline BARBADOS & 11.02453 \\
\hline SAINT LUCIA & 6.029252 \\
\hline MARTINIQUE & 0.189819 \\
\hline COSTA RICA & 0.000000 \\
\hline
\end{tabular}


Table 2: Econometric Results

\begin{tabular}{|lccccccc|}
\hline & $\mathbf{( 1 )}$ & $\mathbf{( 2 )}$ & $\mathbf{( 3 )}$ & $\mathbf{( 4 )}$ & $\mathbf{( 5 )}$ & $\mathbf{( 6 )}$ & $\mathbf{( 7 )}$ \\
\hline RAIN & $1.669^{*}$ & $1.630^{*}$ & $2.518^{* *}$ & $2.814^{*}$ & $2.927^{* *}$ & $2.435^{* *}$ & \\
& $(0.849)$ & $(0.753)$ & $(0.652)$ & $(1.228)$ & $(1.109)$ & $(0.903)$ & \\
TEMP & -6.050 & -6.284 & -5.288 & -6.003 & -6.540 & & \\
& $(8.958)$ & $(8.711)$ & $(8.192)$ & $(6.853)$ & $(7.064)$ & & \\
HD & & -4.551 & -5.372 & -5.373 & -6.129 & & \\
& & $(11.229)$ & $(8.395)$ & $(8.395)$ & $(8.054)$ & & \\
HD & & & $-35.542^{*-1}$ & $-36.213^{*}$ & $-36.841^{*}$ & $-35.820^{*}$ & $-35.500^{*}$ \\
& & & $(16.183)$ & $(14.699)$ & $(14.506)$ & $(16.420)$ & $(16.569)$ \\
HD & & & & 12.037 & 12.830 & & \\
& & & & $(29.219)$ & $(28.985)$ & & \\
HD & & & & & 15.701 & & \\
& & & & & $(14.306)$ & & \\
\hline Grids & 157116 & 157116 & 157116 & 157116 & 157116 & 157116 & 157116 \\
Obs. & 1099812 & 1099812 & 1099812 & 1099812 & 1099812 & 1099812 & 1099812 \\
F( $\boldsymbol{\beta})$ & $4.25^{* *}$ & $7.47^{* *}$ & $52.54^{* *}$ & $98.39^{* *}$ & $214.28^{* *}$ & $13.45^{* *}$ & $4.59^{* *}$ \\
$\mathbf{R}^{2}$ & 0.05 & 0.05 & 0.06 & 0.06 & 0.06 & 0.06 & 0.06 \\
\hline
\end{tabular}


Figure 1: The Typical Structure of a Hurricane



Source: $\underline{\text { http://www.angryconservative.com/home/Portals/O/Blog/GlobalWarming }}$

Figure 2: Wind Field Model Structure

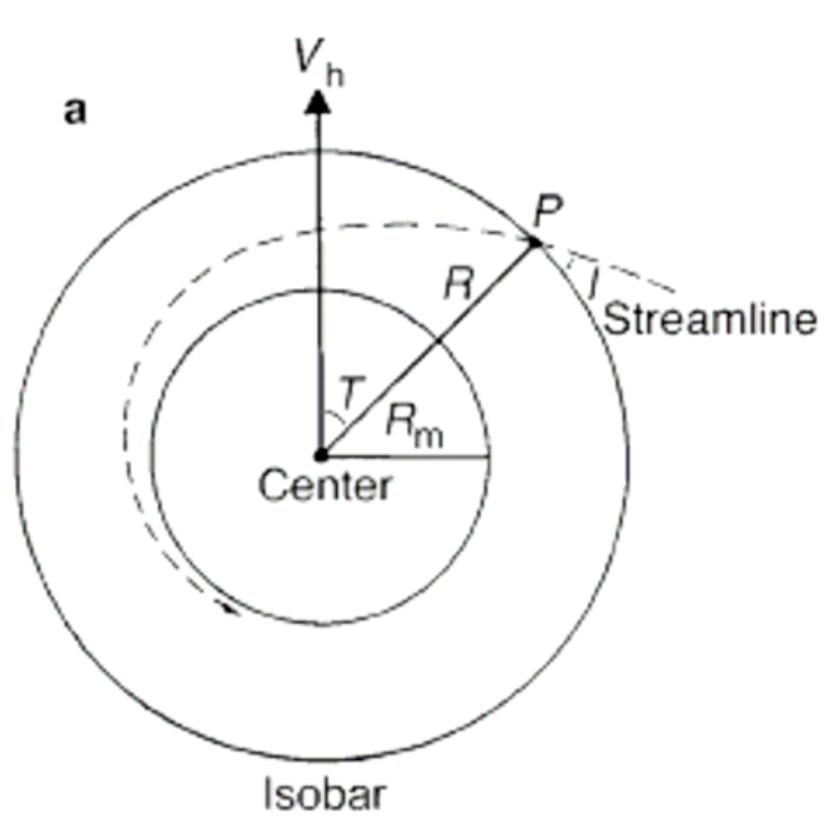

Source: Boose et al (2001) 
Figure 3: Caribbean and Central American (CAC) Region 
Figure 4: All Tropical Cyclone Activity Since 1999



Notes: The red portion of the tracks constitute the segments of tropical storm tracks that reached at least hurricane intensity. 


\section{Figure 5: Cropland Areas in the Caribbean Region}

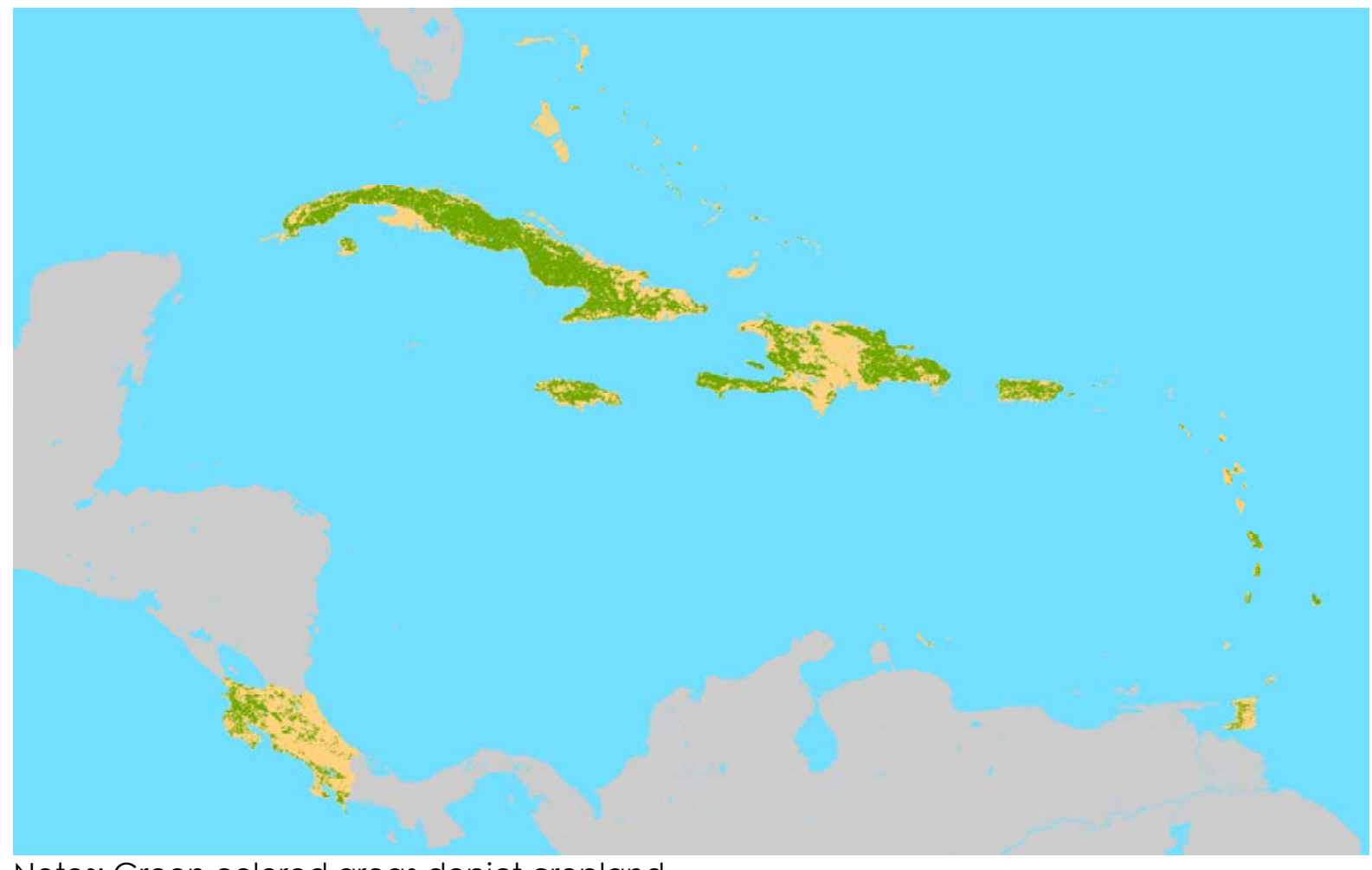

Notes: Green colored areas depict cropland.

Figure 6: Relevant Hurricanes

Notes: The red portion of the tracks constitute the segments of tropical storm tracks that reached at least hurricane intensity. 
Figure 7: Hurricane Dennis (2005)

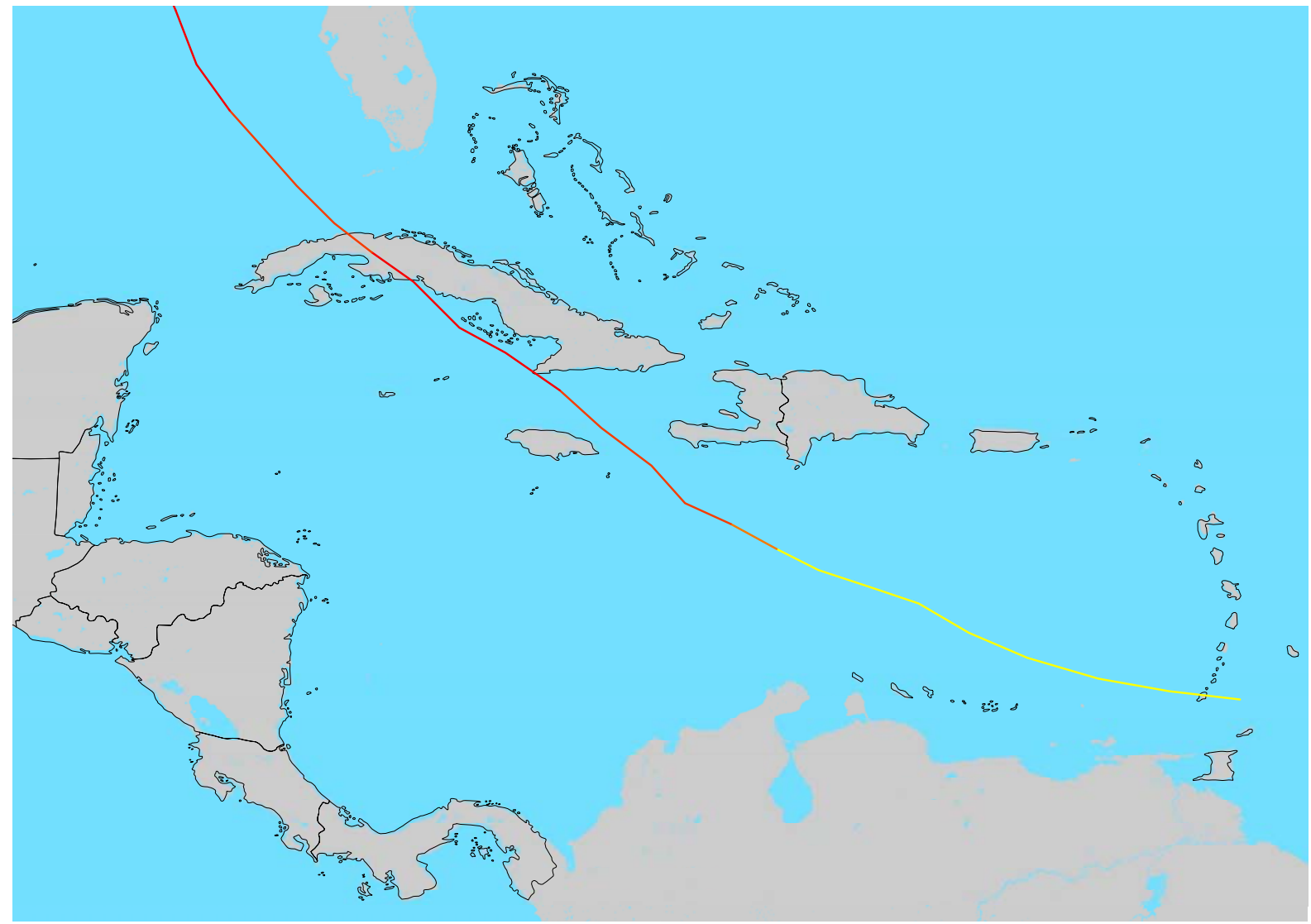

Notes: The red portion of the tracks constitute the segments of tropical storm tracks that reached at least hurricane intensity. 
Figure 8: Hurricane Dennis' (2005) Destruction Path

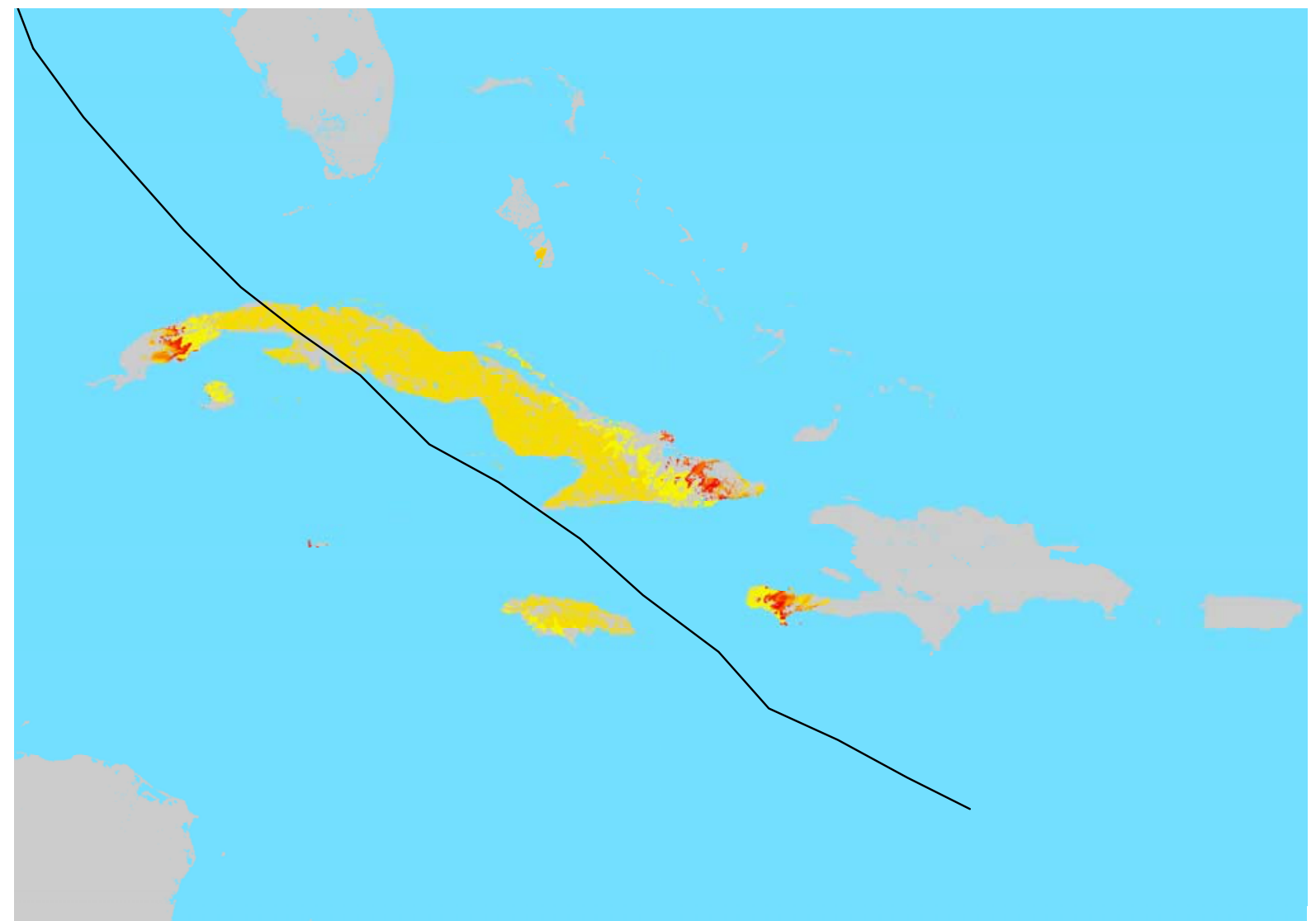

Notes: The degree of destruction increases as the colour scheme changes from yellow to red. 
Figure 9: Average Local Degree of Destruction, 2000-2006



Notes: The degree of destruction increases as the color scheme changes from yellow to red. 